\title{
IIIA
}

AIAA $2002-0508$

\section{Computational Investigation of the Performance and Back-Pressure Limits of a Hypersonic Inlet}

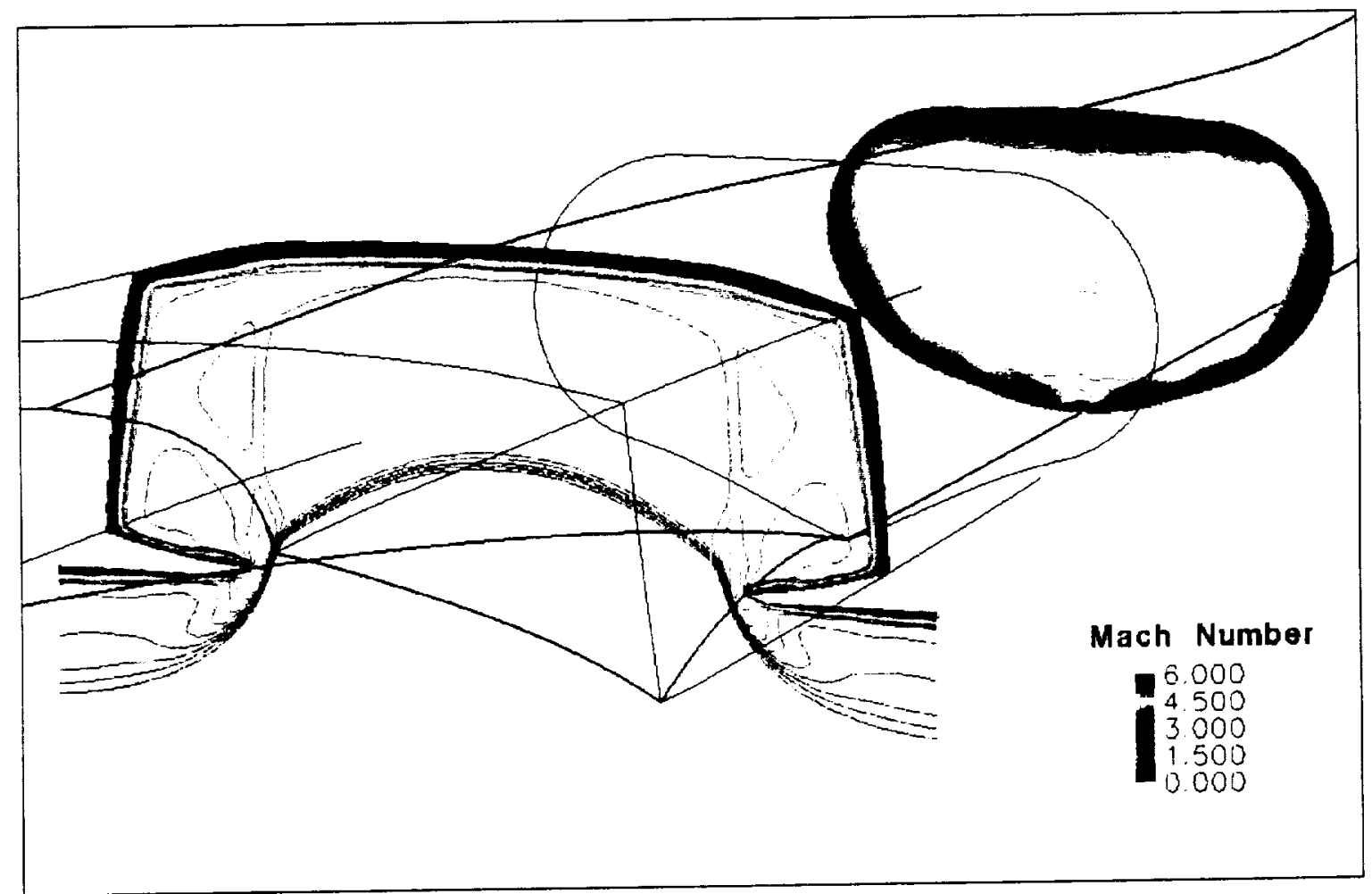

Michael K. Smart

Lockheed Martin Engineering and Sciences

NASA Langley Research Center
Jeffery A. White Hypersonic Airbreathing

Propulsion Branch

\section{0th AIAA Aerospace Sciences Meeting \& Exhibit 14-17 January 2002 / Reno, NV}




\section{Computational Investigation of the Performance and Back-Pressure Limits of a Hypersonic Inlet}

\author{
Michael K. Smart \\ Aeronautical Engineer \\ Lockheed Martin Engineering and \\ Sciences \\ NASA Langley Research Center \\ MS 168, Hampton VA 23681. \\ Jeffery A. White \\ Aerospace Engineer \\ Hypersonic Airbreathing Propulsion \\ Branch \\ NASA Langley Research Center \\ MS 168, Hampton VA 23681.
}

\section{$\underline{\text { Abstract }}$}

A computational analysis of Mach 6.2 operation of a hypersonic inlet with rectangularto-elliptical shape transition has been performed. The results of the computations are compared with experimental data for cases with and without a manually imposed back-pressure. While the no-back-pressure numerical solutions match the general trends of the data, certain features observed in the experiments did not appear in the computational solutions. The reasons for these discrepancies are discussed and possible remedies are suggested. Most importantly, however, the computational analysis increased the understanding of the consequences of certain aspects of the inlet design. This will enable the performance of future inlets of this class to be improved. Computational solutions with back-pressure under-estimated the back-pressure limit observed in the experiments, but did supply significant insight into the character of highly back-pressured inlet flows.

Copyright $(2002$ by M.K.Smart, published by the American Institute of Aeronautics and Astronautics, Inc. with permission.

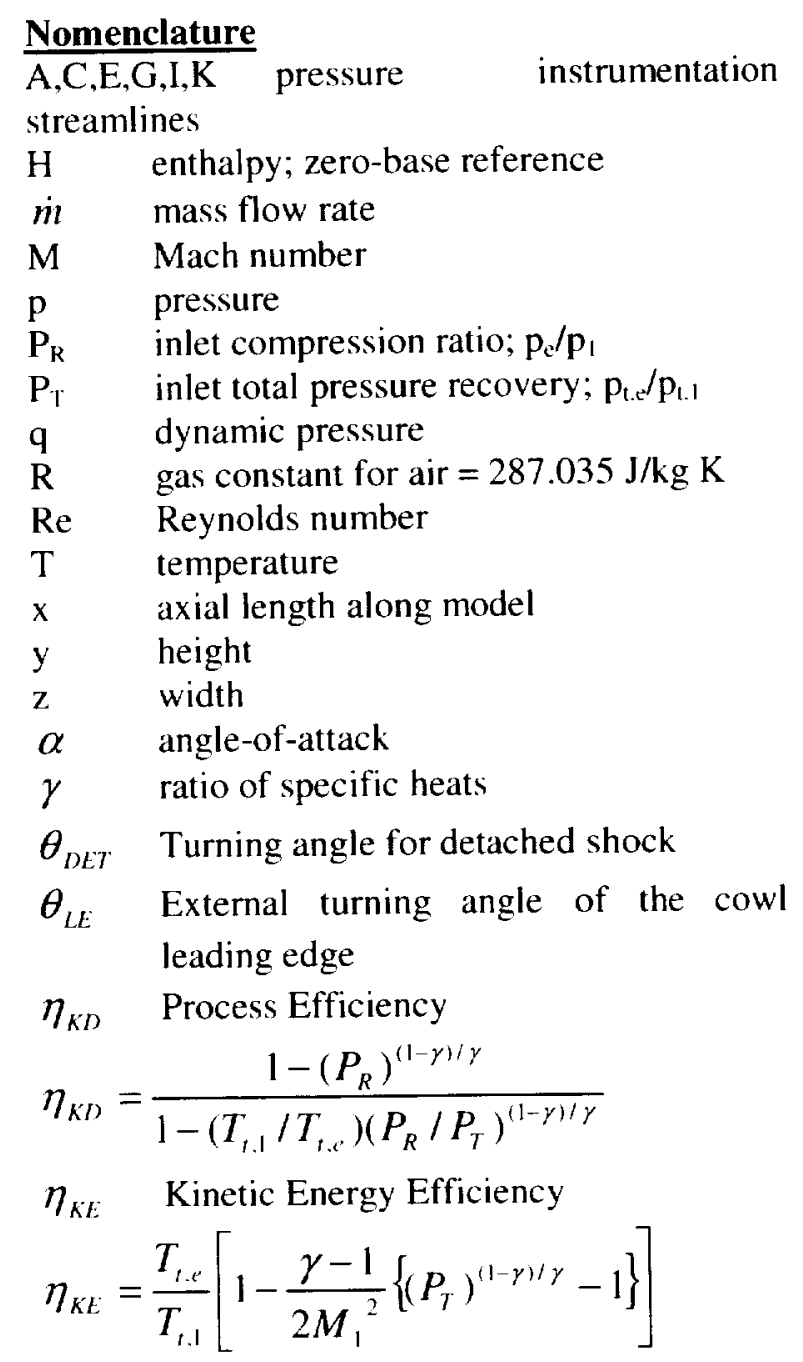

\section{Subscripts}

\begin{tabular}{ll}
\hline I & inlet entrance \\
back & Back-pressure \\
c & stagnation chamber \\
e & inlet exit \\
n & normal \\
t & total \\
t2 & Pitot \\
w & wall
\end{tabular}

\section{Introduction}

The design of efficient inlets for hypersonic vehicles utilizing airframe integrated 
scramjet modules is a subject of interest in the high-speed propulsion community. In these configurations the vehicle bow shock performs the initial compression, and the capture shape for the inlet of each scramjet module is required to be rectangular. Other requirements are that inlets will start before ramjet take-over speeds are reached (Mach 3-4), operate over a large Mach number range, and be efficient during vehicle cruise. For structural and heating reasons, there is also a strong desire to have an intake with fixed geometry and no requirement for boundary layer bleed. Another desirable feature of a hypersonic inlet for some scramjet applications is a transition from a rectangular capture to an elliptical throat. This transition is desirable because the inlet may then be used in combination with an elliptical combustor. An elliptical combustor is superior to a rectangular combustor in terms of the structural weight required to withstand a specified pressure/thermal load, and the level of heat load and viscous drag generated per pound of processed air. Elliptical combustors also reduce undesirable effects associated with hypersonic corner flows.

A detailed methodology for the design of fixed geometry, rectangular-to-elliptical shape transition (REST) inlets was reported in Ref. 1. A description of the experimental testing of a REST inlet with a design point of Mach 6.0 in a hypersonic wind tunnel with a freestream Mach number of 6.2 was reported in Ref. 2. The current paper describes the computational analysis of the Mach 6.0 REST inlet flowfields generated at conditions corresponding to the experiments. ${ }^{2}$ Computational solutions are presented for conditions with and without a manually applied back-pressure.

Experimental Model, Instrumentation and Test Conditions

Figure 1 shows a photograph of the three-dimensional inlet model that was used in the experiments of Ref. 2. The complete model was $175 \mathrm{~cm}$ (69 in.) in length and consisted of the REST inlet, a cruciform rake, a dumpisolator tube, a mass flow meter, and supporting structure. The inlet had highly swept leading edges, a total length of $94.6 \mathrm{~cm}$ (37.2 in), and cowl closure $50.8 \mathrm{~cm}$ (19.9 in) from the most forward point. The throat was $28.6 \mathrm{~cm}$ (11.3 in) downstream of cowl closure, and was followed by a $15.2 \mathrm{~cm}$ ( 6 in) long elliptical isolator. The inlet had an overall contraction ratio of 4.74 and an internal contraction ratio of 2.15. The capture area of $113.8 \mathrm{~cm}^{2}\left(17.6 \mathrm{in}^{2}\right)$ was 15.2 $\mathrm{cm}(6.0 \mathrm{in})$ wide, $11.0 \mathrm{~cm}(4.3 \mathrm{in})$ high at its plane of symmetry, and had sharp leading edges.

Inlet instrumentation consisted of surface pressure taps, Pitot and static pressure probes and co-axial surface thermocouples. Figure 2 shows a schematic of the nominal streamlines along which surface pressure taps were distributed in the inlet. Pressure taps were concentrated on the right-hand side of the model (as the model had a vertical plane of symmetry) and were placed on the six streamlines (labeled A, C, E, G, I and $\mathrm{K}$ in Fig. 2) at 15 different axial stations along the inlet. A photograph of the cruciform rake is shown in Fig. 3. It was installed at the exit of the inlet and contained 24 Pitot probes and 12 static probes. The static probes were equally spaced along the horizontal and vertical branches of the rake, whereas, the Pitot probes were concentrated near the walls to more accurately measure the viscous losses in the inlet. The static probes were designed for internal supersonic flow measurements using the method of Pinckney. ${ }^{3}$

\begin{tabular}{lcc}
\hline \multicolumn{1}{c}{ Property } & Test Point 1 & Test Point 2 \\
\hline $\mathrm{p}_{\mathrm{c}} \mathrm{MPa}(\mathrm{psia})$ & $3.01(437)$ & $2.67(390)$ \\
$\mathrm{H}_{\mathrm{c}} \mathrm{MJ} / \mathrm{kg}(\mathrm{BTU} / \mathrm{lbm})$ & $0.702(302)$ & $0.556(239)$ \\
$\mathrm{M}_{1}$ & 6.176 & 6.178 \\
$\mathrm{p}_{\mathrm{I}} \mathrm{kPa}(\mathrm{psia})$ & $1.393(0.202)$ & $1.241(0.180)$ \\
$\mathrm{T}_{1} \mathrm{~K}\left({ }^{\mathrm{O}} \mathrm{R}\right)$ & $81.1(145.9)$ & $64.0(115.3)$ \\
$\mathrm{p}_{\mathrm{t} .1} \mathrm{MPa}(\mathrm{psia})$ & $2.672(387.5)$ & $2.366(343.1)$ \\
$\mathrm{T}_{\mathrm{t} .1} \mathrm{~K}\left({ }^{\circ} \mathrm{R}\right)$ & $690(1242)$ & $550(991)$ \\
$\mathrm{Re}_{1} \times 10^{6} \mathrm{~m}^{-1}\left(\mathrm{ft}^{-1}\right)$ & $12.0(3.66)$ & $15.6(4.77)$ \\
$\mathrm{q}_{1} \mathrm{kPa}(\mathrm{psf})$ & $37.3(779)$ & $33.2(694)$ \\
$\dot{m}_{1} \mathrm{~kg} / \mathrm{s}(\mathrm{lb} / \mathrm{s})$ & $0.757(1.669)$ & $0.760(1.675)$ \\
$\mathrm{Capture} \mathrm{Area} \mathrm{cm}^{2}$ & $113.8(17.64)$ & $113.8(17.64)$ \\
$\left(\right.$ in $\left.^{2}\right)$ & & \\
\hline
\end{tabular}

Table 1. Wind Tunnel Test Conditions.

The experiments were conducted in the NASA Langley Arc Heated Scramjet Test Facility (AHSTF). ${ }^{4}$ AHSTF Mach 6.2 nozzle calibrations are reported in Ref. 5 for a range of wind tunnel total conditions. These indicated 
that the nozzle flow contained vortex pairs at the mid-point of each wall, and some nonuniformity of properties in the core. The inlet was therefore positioned so that its projected capture tube contained as high a proportion of core flow as possible. Two nominal test points were established for the experimental program. Table 1 lists the facility stagnation chamber conditions for these test points and the equivalent I-D properties of the flow within the inlet capture stream tube. These 1-D properties were used as uniform inflow conditions for the computations.

\section{Computational Analysis}

The NASA Langley code VULCAN ${ }^{6}$ was used to solve the inlet flowfield on typical grids with between 1.17 and 1.25 million grid points. VULCAN is a 3-D, upwind, viscous, compressible flow solver, for cell-centered structured multi-block grids. For the current computations the working fluid was air which was assumed to behave as a calorically perfect gas with $\gamma=1.4$. The two-equation $k-\omega$ model of Wilcox ${ }^{7}$ was used to model the turbulence and the wall matching functions of Wilcox ${ }^{7}$ were also used to reduce the number of grid points required to resolve the wall boundary layers. Both the external flow below the inlet and the internal flow through the inlet were solved.

The computations were performed using a distributed memory parallel (MPI) version of VULCAN on 10 of the $18(667 \mathrm{MHz}$ DEC Alpha 21264 CPU) compute nodes that make up the Hypersonic Airbreathing Propulsion Branch (HAPB) HyprWulf cluster. This parallel cluster runs Ver. 7.0 of the Red Hat Linux operating system and uses the MPICH form of MPI to communicate over a fast Ethernet private network. The CPU time required for a solution without back-pressure was approximately 8 hours. Solutions with back-pressure typically required 48 hours of computation.

The grid topology used for the computations contained either 41 blocks for cases without back-pressure or 43 blocks for cases with back-pressure. Figure 4 presents a side view of the grid on the symmetry plane. The number of regions that the computational domain was decomposed into is also shown in Fig. 4. Regions are defined in VULCAN as a block or a group of blocks that are solved together simultaneously and that are solved using the same algorithm. In this case the regions consist of groups of blocks solved using either a psuedo-temporal space-marching procedure to solve the parabolized NavierStokes (PNS) equations or a spacially elliptic (hyperbolic in time) procedure to solve the full Navier-Stokes (FNS) equations. Each plane of the space-marched regions was converged four orders of magnitude in the root-mean-square of the $\mathrm{L}_{2}$ norm of the residual before advancing to the next plane. The elliptic regions were converged four orders of magnitude in the rootmean-square of the $\mathrm{L}_{2}$ norm of the residual in the aggregate.

Several interesting grid generation techniques were used to improve grid quality and to simplify the grid generation process. The grids used were generated with GRIDGEN such that no singularities (collapsed block faces) were present. This was made possible by employing grid block topologies such as displayed in Fig.5, which shows a portion of the grid used to model the most forward leading edge of the inlet. In addition, discontinuous or non-C $(0)$ block-toblock patching, a new feature recently incorporated into VULCAN, was utilized to simplify the grid generation process. The non$\mathrm{C}(0)$ block-to-block patching allows solution information to be communicated among blocks whose faces are partially or fully collocated but whose face grid point coordinates are not $\mathrm{C}(0)$ continuous across the block-to-block interface.

\section{Computational Results and Comparisons with Experiments}

Two Mach 6.2 nozzle test conditions were included in the experimental test program (Table 1). Two CFD solutions of the inlet were completed for Test Point 2; one with backpressure $\left(T_{w} / T_{t .1}=0.647\right)$ and one without backpressure $\left(\mathrm{T}_{w} / \mathrm{T}_{\mathrm{t} .1}=0.631\right)$. A single $\mathrm{CFD}$ solution without back-pressure $\left(\mathrm{T}_{\mathrm{w}} / \mathrm{T}_{\mathrm{t} .1}=0.438\right)$ was completed for Test Point 1. While the two solutions without back-pressure had different values of $T_{w} / T_{t .1}$ and Reynolds number, the features of the flowfileds were quite similar, so the following discussion of the Test Point 2 
solution without back-pressure is also applicable to the solution performed at Test Point 1 .

The computational results are compared directly with the data collected in the experimental program. ${ }^{2}$ This data was in the form of:

1. Surface pressure measurements along the six instrumentation streamlines.

2. Pitot and static pressure probe measurements at the exit of the inlet.

3. I-D performance properties calculated by integration of the probe data at the exit of the inlet.

\section{CFD solutions without Back-Pressure}

Figure 6 shows the symmetry plane Mach number contours of the computational solution of the REST inlet flowfield at Test Point 2, $\mathrm{T}_{w} / \mathrm{T}_{\mathrm{t}, \mathrm{l}}=0.631, \alpha=0.0^{\mathrm{n}}$ and no backpressure. Note that the shock wave generated by the top and side leading edges of the inlet focuses near the crotch of the cowl, and reflects back towards the top of the inlet where it is substantially cancelled at the inlet throat. A small amount of flow spillage appears below the cowl in Fig. 6; however, the inlet mass capture was computed to be very close to $100 \%$ of the flow in the capture tube, as compared with the value of $96 \%$ obtained from flow-meter measurements in the experiment.

More features of the highly threedimensional inlet flowfield are shown in Fig. 7, which highlights the Mach number contours in two cross-planes normal to the streamwise direction; one plane upstream of the cowl closure and one downstream of the crotch but before the throat. The axial positions of these cross-planes are shown in Fig. 6. Note the curved nature of the shock generated by the top and side leading edges (shown in the leading cross-plane) and also that it was not attached to the cowl leading edges. Also note that the reflected cowl shock is curved and essentially sweeps across the cowl and side of the inlet as it propagates downstream to the throat. The interaction of the swept cowl shock with the inlet boundary layer produces some local bulging of the cowl boundary layer.

Shock detachment at the cowl leading edges was an unexpected feature of the REST inlet flowfield at the slightly over-sped conditions of the current work. The shape of the highly swept cowl leading edges was determined in the inlet design procedure' to be coincident with the shock generated by the top and side leading edges at the design point of Mach 6.0. However, for a shock to remain attached to a swept leading edge, the external turning angle of the leading edge must be less than the shock detachment angle normal to the leading edge. Figure 8 shows a plot of the normal Mach number $\left(M_{n}\right)$, the external angle of the cowl leading edge $\left(\theta_{L E}\right)$, and the shock detachment angle $\left(\theta_{D E T}\right)$ corresponding to $\mathrm{M}_{\mathrm{n}}$, versus streamwise distance along the cowl leading edges. It is clear from Fig. 8 that $\theta_{L E}>\theta_{D E T}$ along a good proportion of the length of the cowl leading edges. Hence the shock detachment shown in Fig. 7 should be present at Mach 6.2 for this inlet. Reduction of $\theta_{l E}$ such that $\theta_{L E}<\theta_{D E T}$ along the length of the cowl would be expected to improve inlet efficiency at conditions close to the design point of Mach 6.0. At conditions below Mach 6.0 the shock from the top and side leading edges passes below the cowl leading edges with no adverse effects.

Figure 9 shows a comparison of the experimental and CFD generated surface pressure distributions along the instrumentation streamlines (Fig. 2). In the portion of the inlet upstream of the crotch the experimental and computational pressure distributions are almost identical. Downstream of the crotch the experimental and computational distributions show the same trends and attain similar pressure levels at the exit. However, the experimental data showed evidence of a shock wave beginning on the cowl (streamline I) at $x=32$ in. that propagated downstream until it reached the top of the inlet (streamline A) at $x=37$ in.

Figure 10(a) shows the normalized Pitot and static pressure distributions on the horizontal branch of the exit rake, along with the corresponding computational results. The CFD and experimental values match reasonably well, except near the center of the rake where the experimental Pitot pressure is lower and the experimental static pressure is higher than in the computation. Figure 10(b) shows a comparison of the Mach number and total pressure 
distributions calculated from these rake measurements with the computation. As one would expect, the experiment and CFD match up reasonably well away from the center of the rake, but the differences near the symmetry plane are even more pronounced than in Fig. 10(a). The reduced Pitot to static pressure ratio in the experiment leads to a noticeable dip in the Mach number in the center of the rake and a corresponding drop in total pressure. In contrast, the computational solution showed no evidence of any drop in the Mach number or total pressure near the center of the rake. Probe interference and other problems associated with rake measurements have been ruled out as causes of the phenomenon. ${ }^{2}$

Figure 11(a) shows the normalized Pitot and static pressure distributions on the vertical branch of the exit rake, along with the corresponding computational results. Here the differences between the experimental and computational results are more pronounced. While the Pitot pressure distributions peaks at approximately $y=0.4$ in. for both experiment and computation, the experimental Pitot pressure drops well below the computational values on the lower half of the rake. The values of static pressure are fairly uniform and reasonably well matched in the lower two-thirds of the rake, but the experimental static pressure jumps by approximately $50 \%$ in the top one-third of the rake, while the computational value remains at the same level. The sudden rise in static pressure near the top of the rake is further evidence of a shock propagating down the inlet (also indicated by the experimental surface pressure distributions of Fig. 9). Figure 11(b) shows the Mach number and total pressure distributions calculated from the vertical rake measurements together with the corresponding computational values. The figure clearly shows the presence of a region of low momentum flow adjacent to the center of the cowl in the experimental data that is absent from the computational solution.

To begin a discussion of the reasons for the differences between the experimental measurements and the computational solutions, it is important to note that the CFD solution shows an inlet flowfield that is close to what was expected for the REST inlet at slightly over-sped conditions and uniform inflow. Therefore, differences between the experiment and the CFD must either be due to differences in the inflow conditions, deficiencies in the computational model or some unexpected flow phenomenon. The major differences between the experimental measurements and the computational solution were the presence of a shock wave propagating downstream of the inlet throat, and the presence of a region of low momentum flow near the cowl at the inlet exit. After significant investigation of all aspects of the experimental program and the computational analysis, some possible causes of these differences are:

1. The assumption of uniform inflow conditions in the computations.

2. Inadequate modeling of the flow near the inlet side leading edges.

3. A small positive angle-of-attack of the inlet relative to the nozzle during the experiments.

With regard to (1), the non-uniform experimental inlet capture flow was approximated in the computations as a uniform inflow with the same 1-D integrated quantities as the capture streamtube of the inlet. The loss of detail associated with this approximation may be responsible for some of the observed differences between the experiment and the computation. In order to resolve this issue, CFD solutions must be completed with a non-uniform inflow that matches the nozzle calibrations.

With regard to (2), in order to simplify the blocking structure and reduce computation time, no attempt was made to compute the flow adjacent to the sides of the inlet. As long as flow was attached at the side leading edges of the inlet, this simplification does not affect the accuracy of the solution. During the reexamination of the modeling assumptions made in the computational solution, a shock detachment analysis of the side leading edges (similar to that shown in Fig. 8 for the cowl) was performed. The results of this analysis indicated that the external angle of the inlet side leading edge was above the local shock detachment angle over a portion of its length. It is therefore probable that flow was not attached to the side leading edges in the experiment. Extra computational blocks must be added to determine if losses associated with a detached 
side leading edge shock are responsible for the observed differences between the experimental data and computational results.

With regard to (3), the sensitivity of the inlet flowfield to positive angle-of-attack is indicated by a comparison between Figs. 12(a) and (b), which show the distribution of normalized total pressure at the exit of the inlet for computations with $\alpha=0.0^{\circ}$ and $0.5^{\circ}$. Both Figs. 12(a) and (b) show the boundary layer on the top and sides of the inlet and a clearly defined core flow. For $\alpha=0.0^{\circ}$, the cowl boundary layer bulges on either side of the symmetry plane due to its interaction with the swept cowl shock. There is also a region of the core flow above the center of the cowl with relatively low total pressure. For $\alpha=0.5^{\circ}$, the off-center cowl boundary layer bulges become more defined and have increased in size. Furthermore, the low total pressure region above the center of the cowl now extends all the way to the horizontal rake. These differences between the computational solution at $\alpha=0.0^{\circ}$ and $0.5^{\circ}$ are similar to the differences between the $\alpha=0.0^{\circ}$ computation and the experiment. Therefore it is possible that some inadvertent positive angle-of-attack could be contributing to the observed differences.

As an addition to this discussion, some further computational solutions were performed to investigate the effect of reduced cowl leading edge external angle. In particular, $\theta_{L E}$ was reduced to the point where a shock detachment analysis indicated that $\theta_{L E}<\theta_{D E T}$ along the entire length of the cowl. Interestingly, the computational solution of this inlet geometry continued to show shock detachment along the length of the cowl leading edges, however with significantly reduced stand-off. Figure 13 shows the distribution of total pressure ratio at the inlet exit for this computation. A comparison between Figs. 12(a) and 13 indicates that reduced cowl leading edge shock stand-off reduced the scale of the cowl boundary layer bulges. Hence the cowl leading edge external angle is an important parameter in the overall design of a REST inlet.

Equivalent one-dimensional inlet performance properties were calculated in Ref. 2 by dividing the inlet exit area into four sections and constructing a series of elliptical-annular strips on each Pitot probe in the horizontal and vertical branches of the rake. Properties at each Pitot probe were assumed to correspond to the average value over the strip, and equivalent 1-D properties were calculated by integration over all the strips. ${ }^{2}$ Given that probes on the lower portion of the vertical rake were positioned in an area of particularly low momentum flow, it is believed that experimental 1-D parameters calculated in this way are skewed to indicate lower performance than delivered by the actual inlet. Figure 14 shows equivalent 1-D mass flow weighted values of total pressure recovery $\left(\mathrm{P}_{\mathrm{T}}\right)$, kinetic energy efficiency $\left(\eta_{K E}\right)$ and process efficiency $\left(\eta_{K D}\right)$, versus wall-to-total temperature ratio $\left(\mathrm{T}_{\mathrm{w}} / \mathrm{T}_{t .1}\right)$, based on the experimental rake data (as just described) and integration of the computational solution over the entire inlet exit. The computational solutions show considerably more efficient inlet operation than indicated by the experimental values. The efficiency of the actual inlet is believed to be somewhere between the two.

\section{CFD Solutions with Back-Pressure}

Numerical simulation of inlet operation with an imposed back-pressure can require up to an order of magnitude increase in computational time as compared to cases without backpressure. Furthermore, full computation of highly back-pressured flowfields generated in the complete inlet/dump-isolator/flow-meter geometry in the current work, would require a significant increase in the grid size and complexity beyond the no-back-pressure grid. As an alternative to solving the full inlet/dumpisolator/flow-meter flowfield, the back-pressure performance of the REST inlet was computed in the current study by solving the flowfield generated by applying a back-pressure to a long constant area tube connected downstream of the inlet exit. This geometry, which can be viewed as modeling a REST inlet with a very long constant area isolator, significantly decreased the grid complexity and computational time for a back-pressured computation, while still supplying a detailed solution of the flowfield in a back-pressured REST inlet. A subsonic, constant pressure boundary condition was 
applied at the end of the tube, and the length of tube required to perform this computation was increased until a solution could be established with no reversed flow at the exit.

Figure 15 shows the symmetry plane pressure contours for the computational solution of the REST inlet at Test Point 2, $\mathrm{T}_{\mathrm{w}} / \mathrm{T}_{\mathrm{t} . \mathrm{l}}=$ $0.647, \alpha=0.0^{\circ}$ and $P_{\text {back }}=195 \mathrm{kPa}$. For clarity, only the fully closed portion of the inlet is shown in Fig. 15, along with the tube extension. It can be seen that the imposed back-pressure generated an asymmetric shock train which stabilizes just downstream of the inlet throat. The shock train feeds furthest upstream on the top of the inlet due to the presence of the relatively thick top wall boundary layer. The initial wave in the train emanates from the top of the inlet and sweeps downstream to the cowl before undergoing numerous reflections in a decreasing area. The flow adjacent to the top of the inlet is separated by the initial shock and remains highly distorted along the full length of the inlet and tube extension.

Figure 16 shows the Mach number contours in three cross planes normal to the streamwise direction, giving a more complete view of the highly three-dimensional backpressured flowfield. The axial positions of these cross-planes are indicated in Fig. 15. The most upstream cross-plane is well ahead of the throat and is not effected by the back-pressure. The middle cross-plane is just downstream of the throat and shows an area of highly distorted flow spread around the top and sides of the inlet. However, the cowl boundary layer remains unaffected by the back-pressure. The final cross-plane is at the exit of the inlet and indicates that the highly distorted flow on the top and sides of the inlet has formed into two off-center lobes that extend at least two-thirds of the distance to the cowl. In this plane the shock train is concentrated in the center of the inlet in a region adjacent to the cowl.

As far as comparisons between the back-pressured computational results and the experiments are concerned, it was observed in the experiment that the inlet could support a significantly higher back-pressure than indicated by the CFD. In other words, the inlet exhibited the ability to support a stable shock train further upstream than was possible in a fully converged computational solution. Computations with $\mathrm{P}_{\text {hack }}$ $>195 \mathrm{kPa}$ either did not fully converge, or the shock train moved too far upstream and unstarted the inlet. Figure 17 shows a comparison of the experimental surface pressure distributions along instrumentation streamlines at the maximum back-pressure condition, with the computational results at $P_{\text {back }}=195 \mathrm{kPa}$. The experimental plots clearly show that a disturbance stablized well upstream of the inlet throat, and that pressure distributions on each streamline were quite similar downstream of cowl closure. In contrast, the computational solutions show a disturbance slightly upstream of the inlet throat at the top of the inlet (streamline A), and considerable variation between the pressure distributions on each streamline.

The reasons why the computational solution would not converge at the backpressure levels observed in the experiments is not known. It should be recognized, however, that back-pressured flowfields contain large scale separated regions, shear layers well away from surfaces and extremely complicated shock wave interactions. It may be that current turbulence models used in the framework of the Reynolds averaged Navier-Stokes equations, are not sufficiently developed to enable prediction of hypersonic inlet back-pressure limits.

\section{Conclusions}

Results of the computational analysis of Mach 6.2 operation of a three-dimensional hypersonic inlet were reported. The fixed geometry inlet had a design point of Mach 6.0, an overall contraction ratio of 4.74 and an internal contraction ratio of 2.15 . It also featured highly swept leading edges and a smooth transition from a nearly rectangular capture to an elliptical throat. The computations were conducted in concert with a previously reported experimental testing program to (1) compare the computational and experimental results, and (2) supply detailed information about the inlet flowfield that cannot be obtained from experiment. Computations with and without a manually imposed back-pressure were included in the study.

While the numerical solutions of the noback-pressure flowfields accurately predicted 
the overall compression ratio and surface pressure distributions in the inlet, comparisons with the experimental data indicated that a number of features observed in the experiments did not appear in the computations. These included a shock wave that persisted downstream of the inlet throat; and a region of low momentum flow that was observed near the cowl at the inlet exit. The absence of the low momentum region in the computations led to a prediction of more efficient inlet operation than was observed in the experiment. Possible reasons for the discrepancies between the experiment and computations are:

1. The assumption of uniform inflow conditions in the computations.

2. Inadequate computational modeling of the flow near the inlet side leading edges.

3. A small positive angle-of-attack of the inlet relative to the nozzle during the experiments.

It is currently planned to introduce remedies for (1) and (2) in the near future, at which point the affect of (3) can be more accurately assessed.

The computational solutions supplied great insight into some inadvertent features of the flowfields generated by operating inlets of this class at slightly over-sped conditions. In particular, the problem of shock detachment on the cowl leading edges due to excessive external leading edge angle. Computational solutions with reduced external leading edge angle indicated that losses associated with this shock detachment had a considerable effect on the character of the overall flow at the inlet exit. In this instance CFD has been a valuable tool for recognizing the impact of cowl leading edge external angle on the overall performance of the inlet.

Highly back-pressured inlet operation was modeled with a simplified grid topology that substituted a long constant area tube for the more complicated geometry used in the experiments. These computations showed that an imposed back-pressure generated an asymmetric oblique shock train just downstream of the throat which separated the top and side wall boundary layer. Flow near the top of the inlet remained highly distorted due to the presence of the shock train. Comparisons with experiment indicated that the CFD underpredicted the back-pressure limit of the REST inlet. This may be a consequence of inadequacies in the modeling of turbulence.

\section{References}

'Smart, M.K., "Design of ThreeDimensional Hypersonic Inlets with Rectangular-to-Elliptical Shape Transition", Journal of Propulsion and Power, Vol. 15, No. 3 , pp 408-416, 1999.

${ }^{2}$ Smart, M.K., "Experimental Testing of a Hypersonic Inlets with Rectangular-toElliptical Shape Transition", Journal of Propulsion and Power, Vol. 17, No. 2, pp 276$283,2001$.

'Pinckney, S.Z., "An Improved Static Probe Design", AIAA Journal, Vol. 12, No. 4, p 562, 1974.

${ }^{+}$Guy, R.W., Rogers, R.C., Puster, R.L., Rock, K.E., and Diskin, G.S., "The NASA Langley Scramjet Test Complex", AIAA Paper No. 96-3243, 32nd AIAA/ASME/SAE/ASEE Joint Propulsion Conference, July 1-3, 1996.

${ }^{5}$ Thomas, S.R., Voland, R.T., and Guy, R.W., "Test Flow Calibration Study of the Langley Arc-Heated Scramjet Test Facility", AIAA paper No. 87-2165, 23rd Joint Propulsion Conference, San Diego, California, June 1987.

${ }^{6}$ White, J.A., and Morrison, J.H., "A pseudo-temporal multi-grid relaxation scheme for solving the parabolized Navier-Stokes equations", AIAA Paper 99-3360, $14^{\text {th }}$ AIAA Computational Fluid Dynamics Conference, Norfolk VA, June 1999.

${ }^{7}$ Wilcox, D. C., Turbulence Modeling for CFD, $2^{\text {nd }}$ Edition, DCW Industries Inc., 1998. 


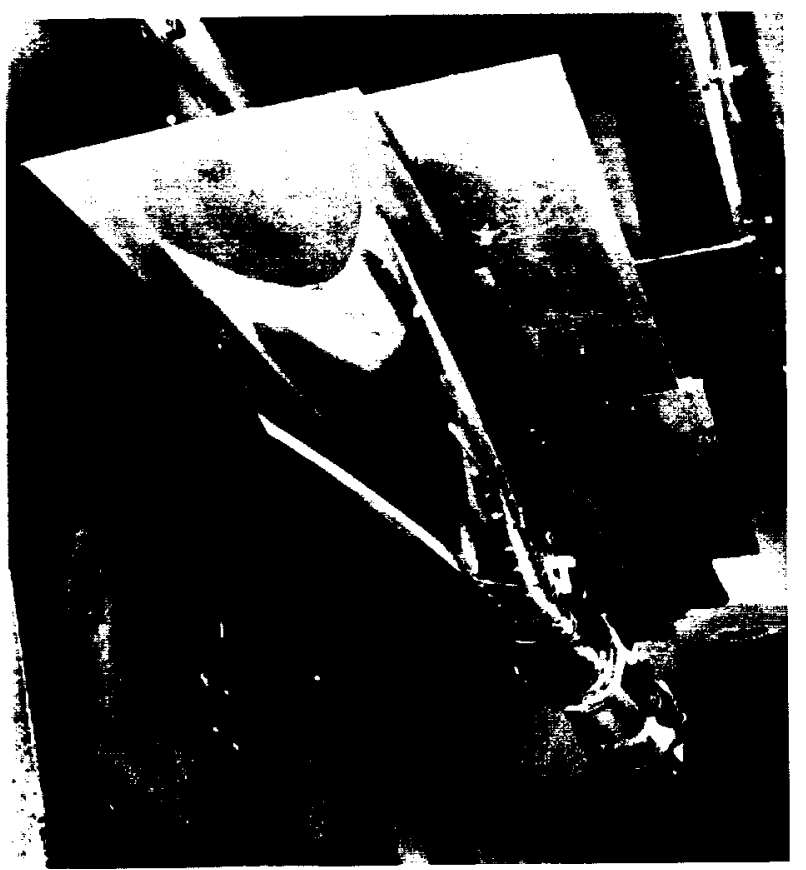

Figure 1- Photograph of the fully assembled REST inlet model in the AHSTF test section

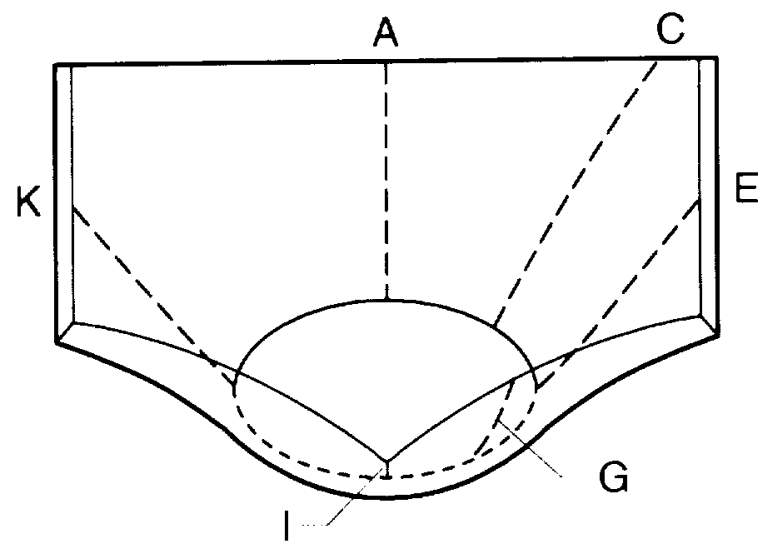

Figure 2 - Schematic of the surface pressure instrumentation streamlines

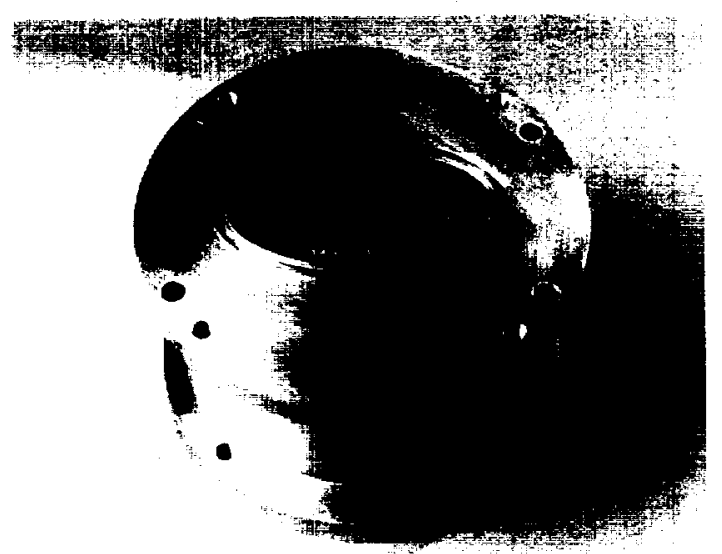

Figure 3 - Photograph of the cruciform rake at inlet exit

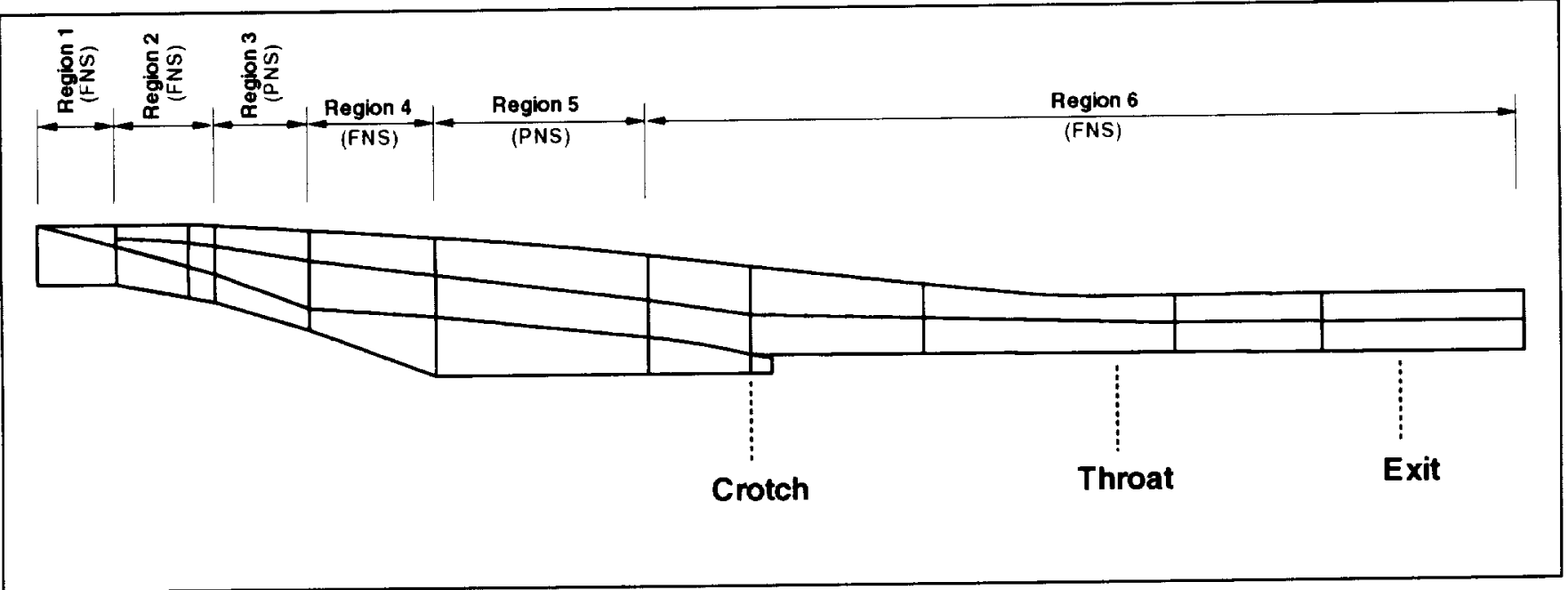

Figure 4 - Schematic of the computational grid topology and region structure 


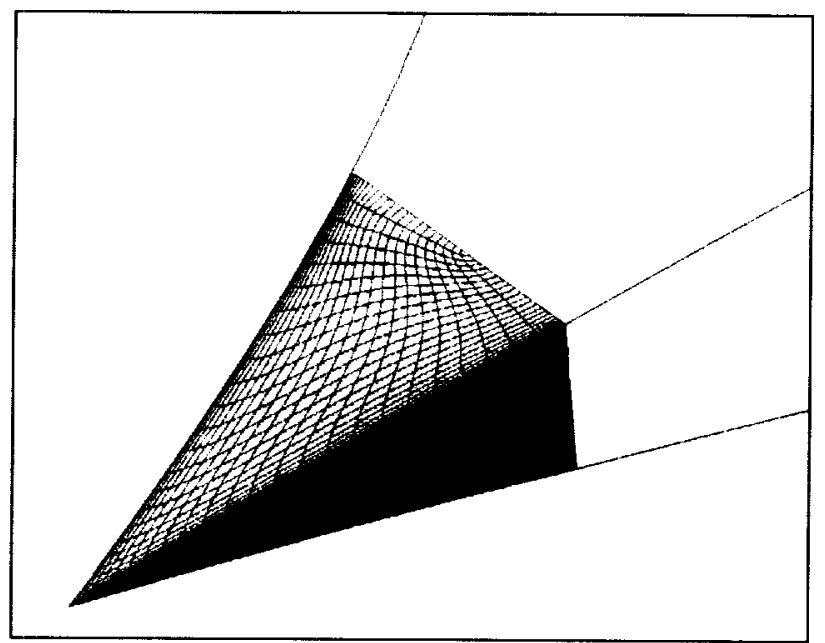

Figure 5 - Typical grid topology used for swept leading edges

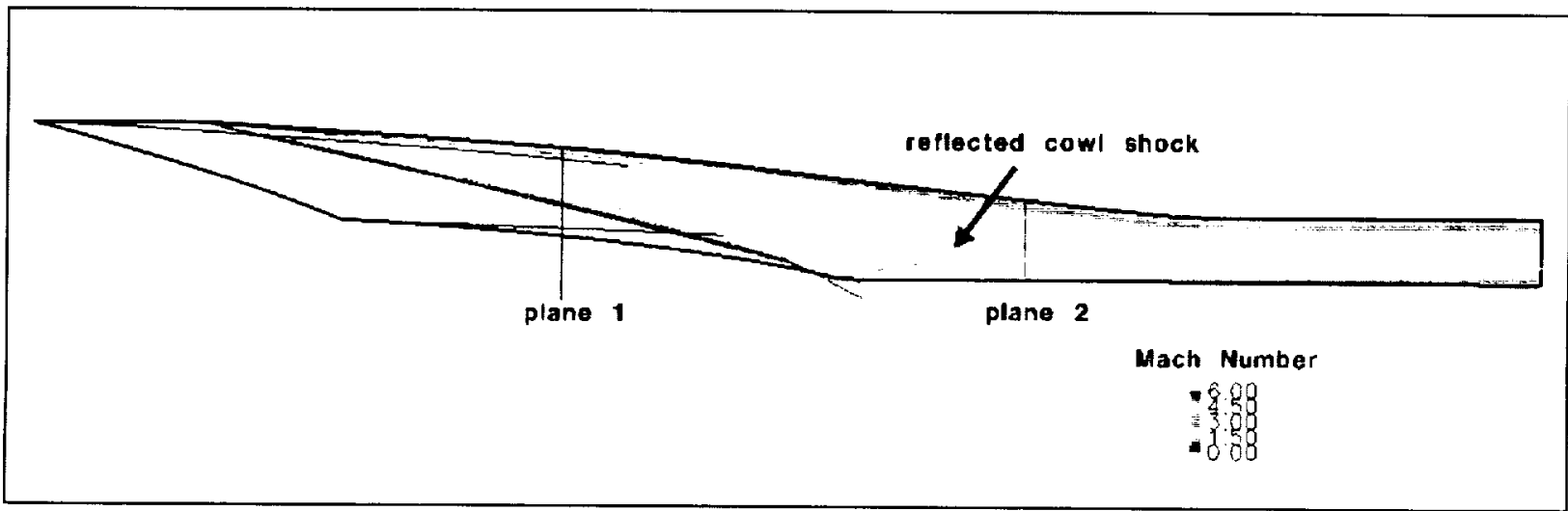

Figure 6 - Symmetry plane Mach number contours

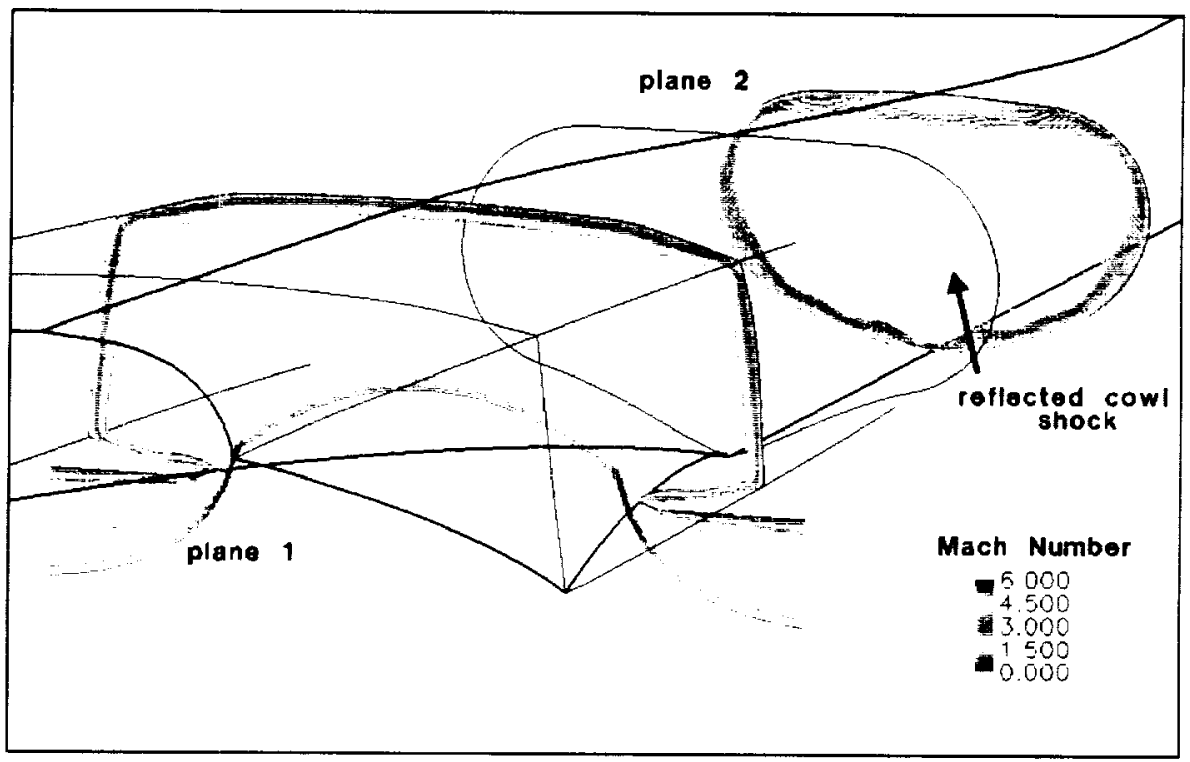

Figure 7 - Mach number contours in cross-planes before and after cowl closure 


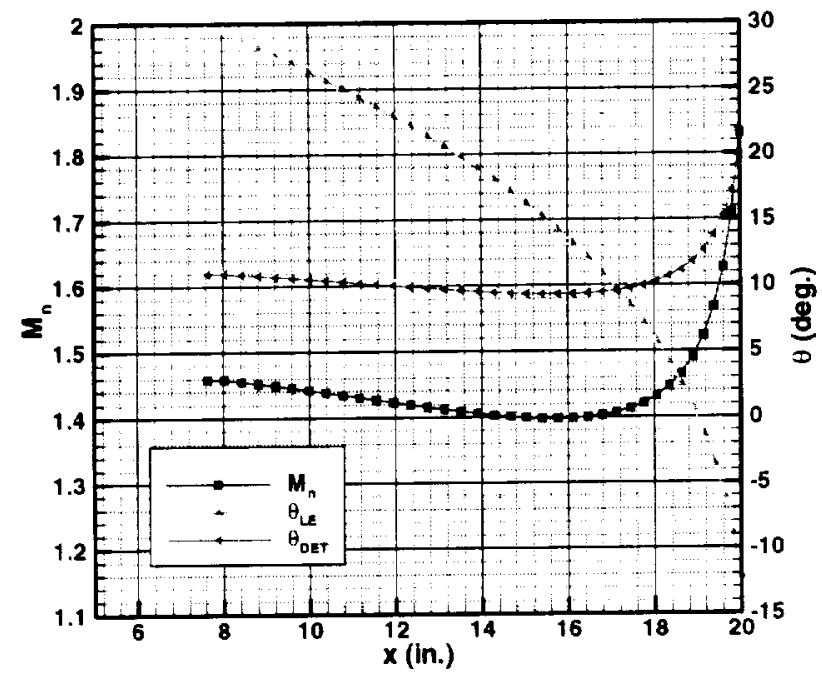

Figure 8 - Results of the cowl leading edge shock detachment analysis

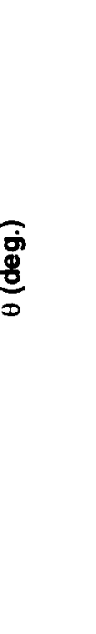

(n)

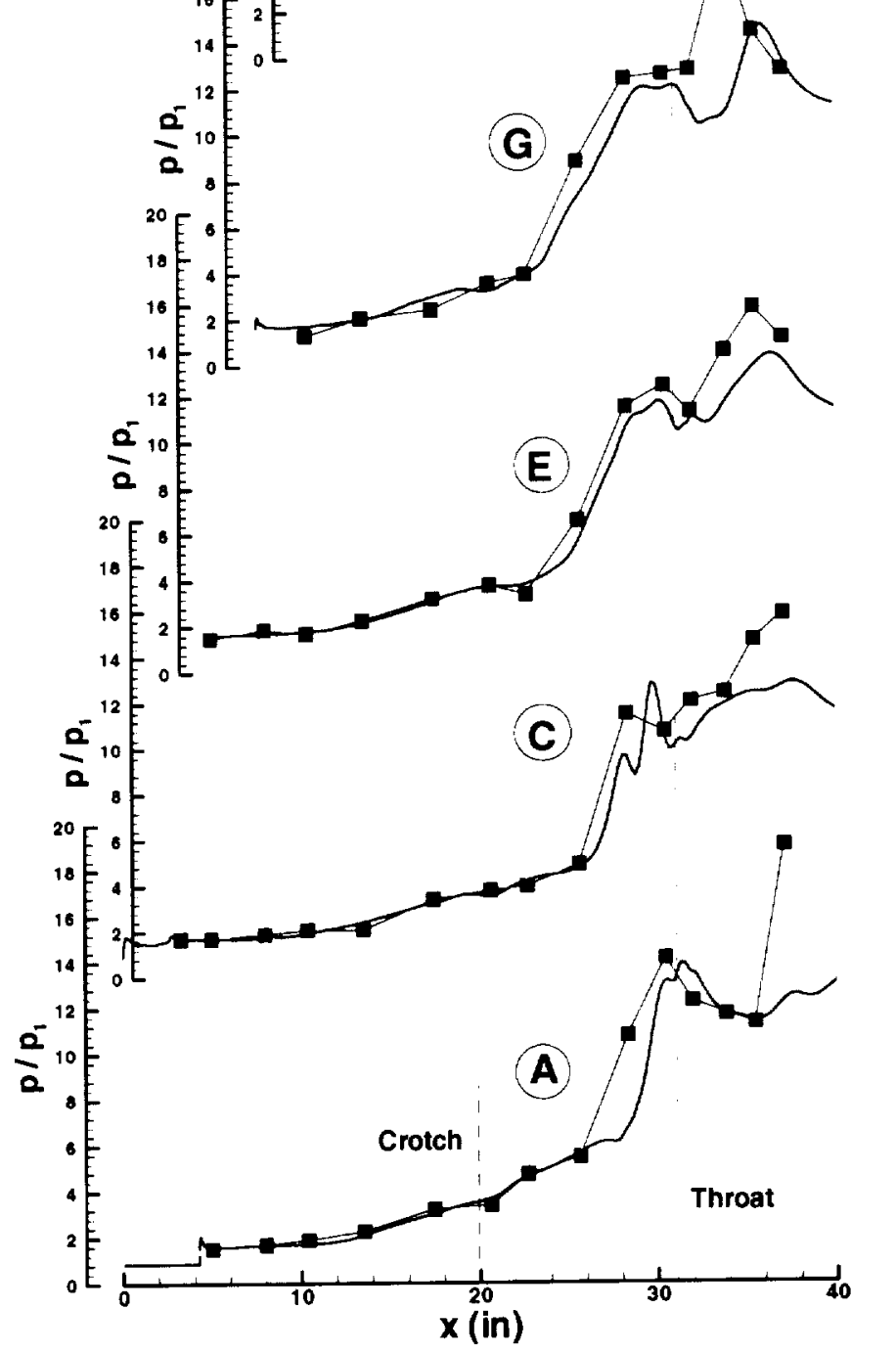

Figure 9 - Surface pressure comparisons along instrumentation streamlines 


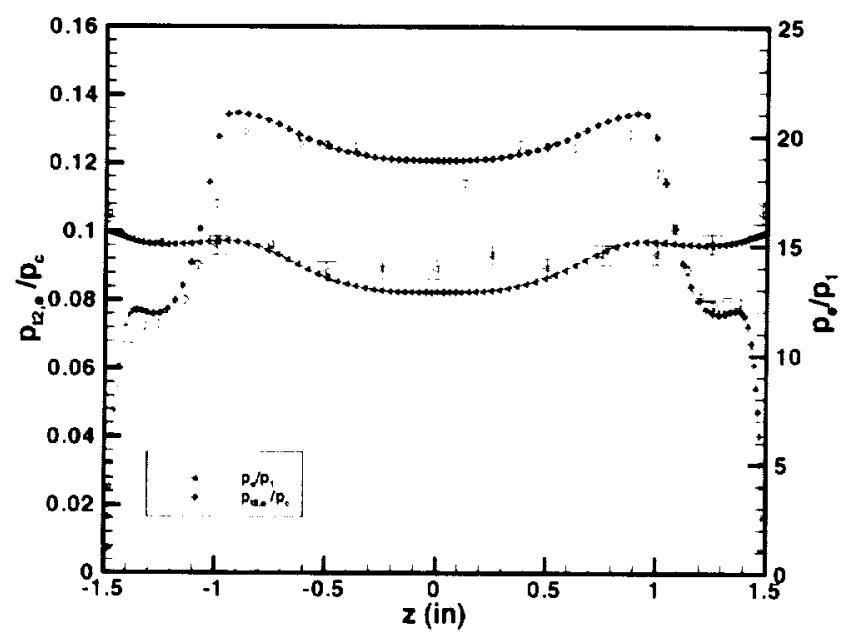

(a) Static and Pitot pressure distributions

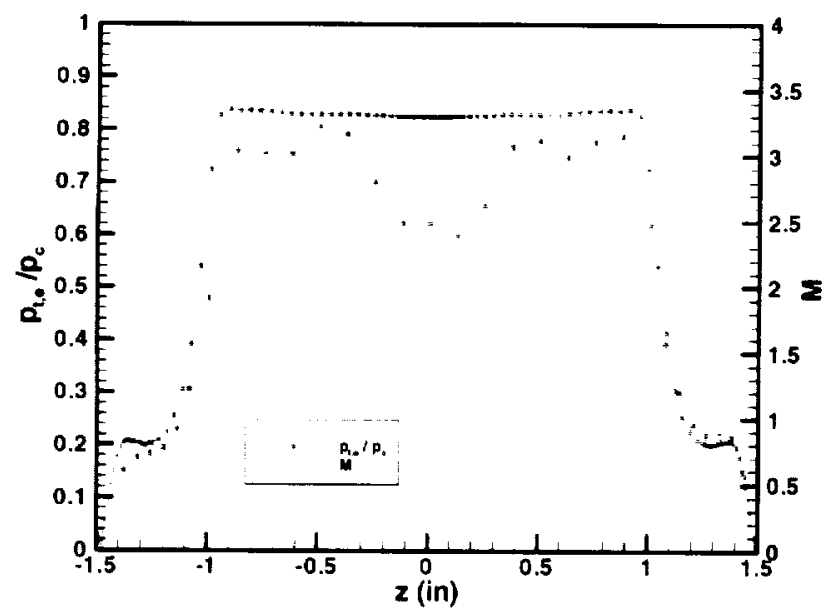

(b) Mach number and total pressure distributions

Figure 10 - Experimental and computational comparisons on the Horizontal branch of the rake

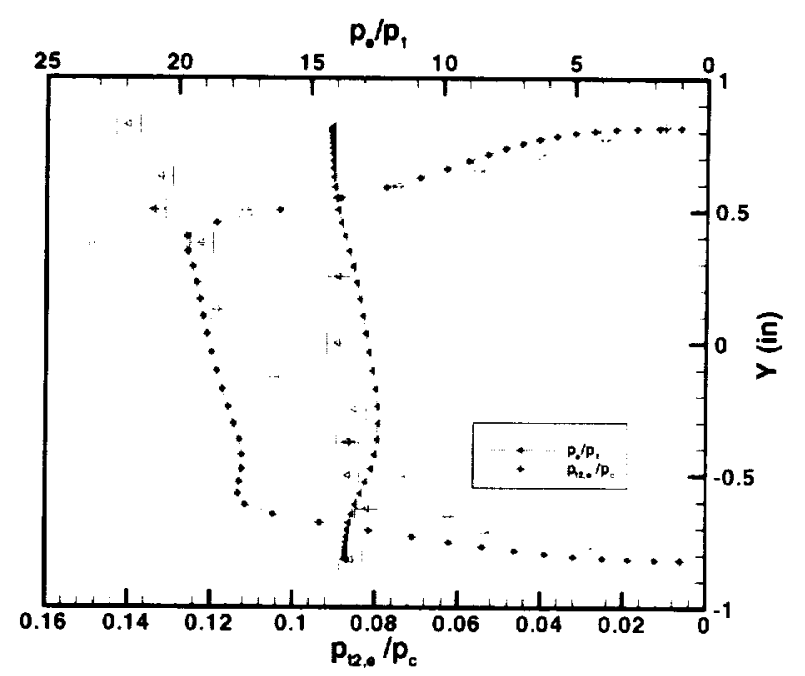

(a) Static and Pitot pressure distributions

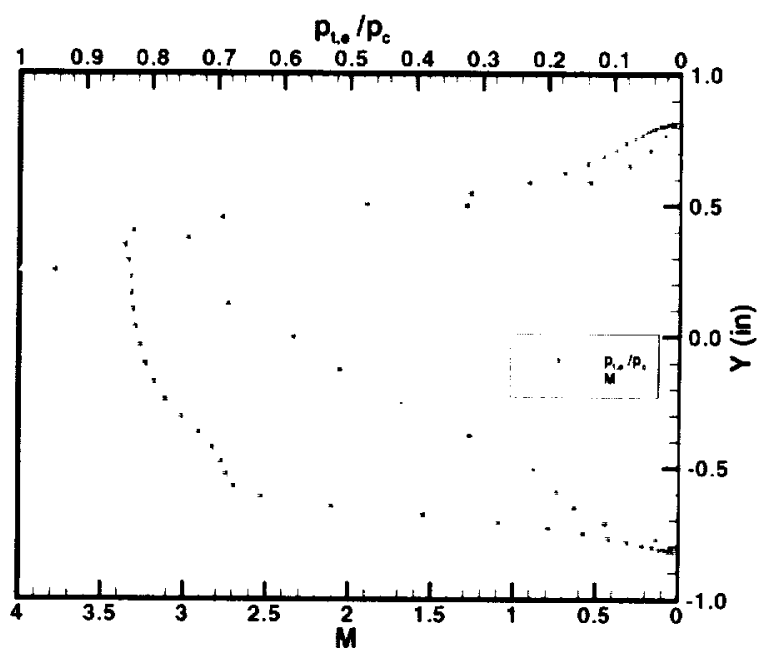

(b) Mach number and total pressure distributions

Figure 11 - Experimental and computational comparisons on the vertical branch of the rake 


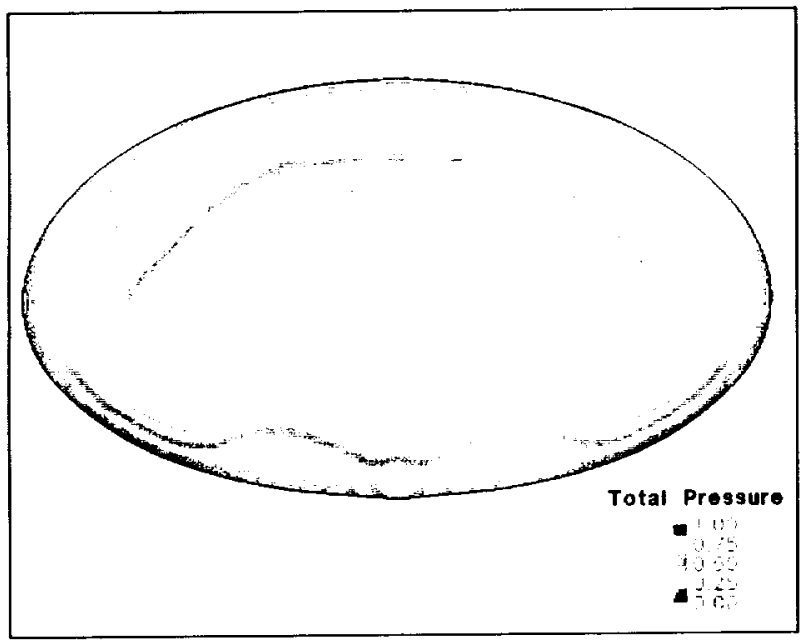

(a) $\alpha=\mathbf{0 . 0}$

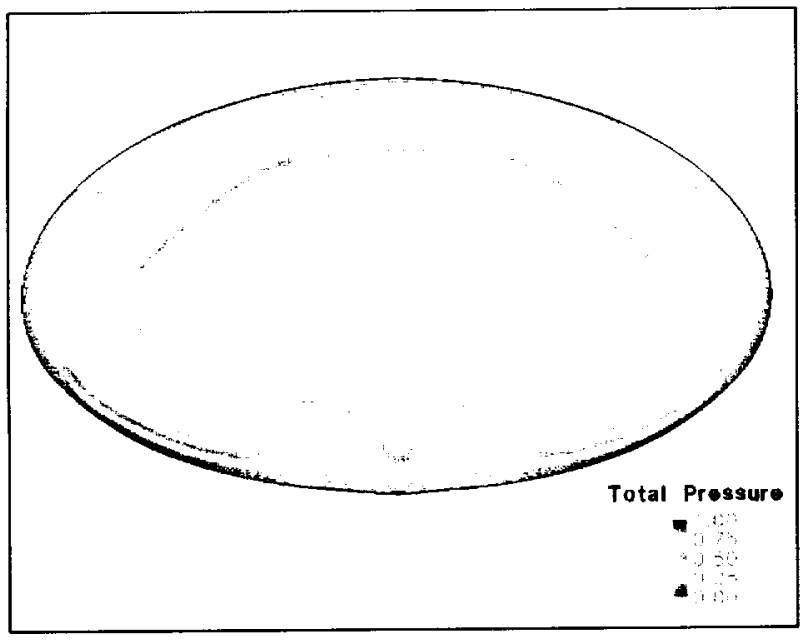

(b) $\alpha=0.5^{\prime \prime}$

Figure 12 Total pressure distributions at the inlet exit

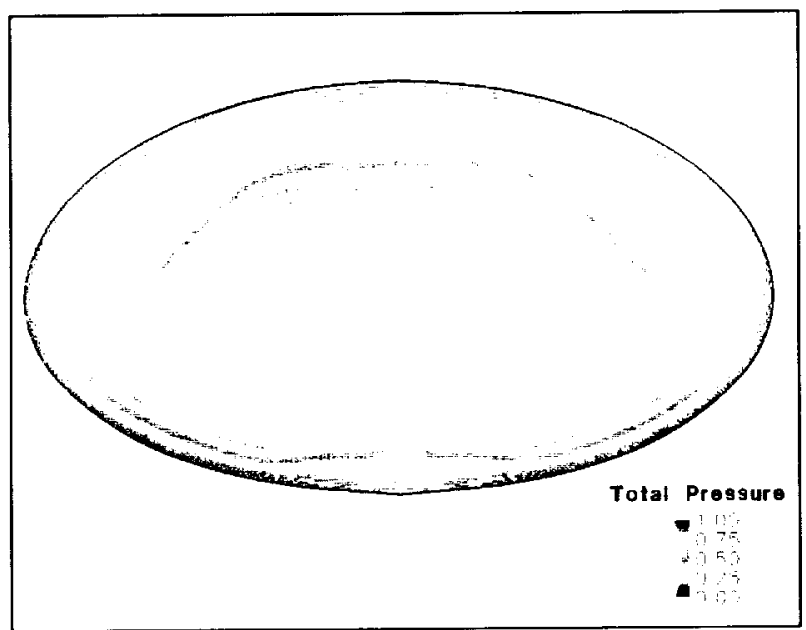

Figure 13 Total pressure distribution at the inlet exit with

$$
\theta_{I E}<\theta_{D E T}
$$

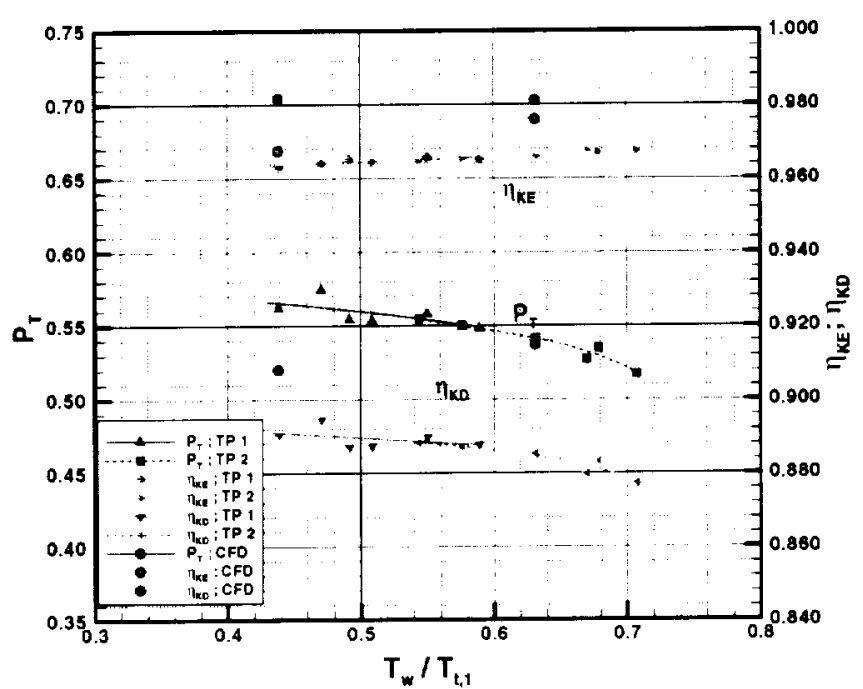

Figure 14 - Equivalent 1-D efficiency parameters at the inlet exit 


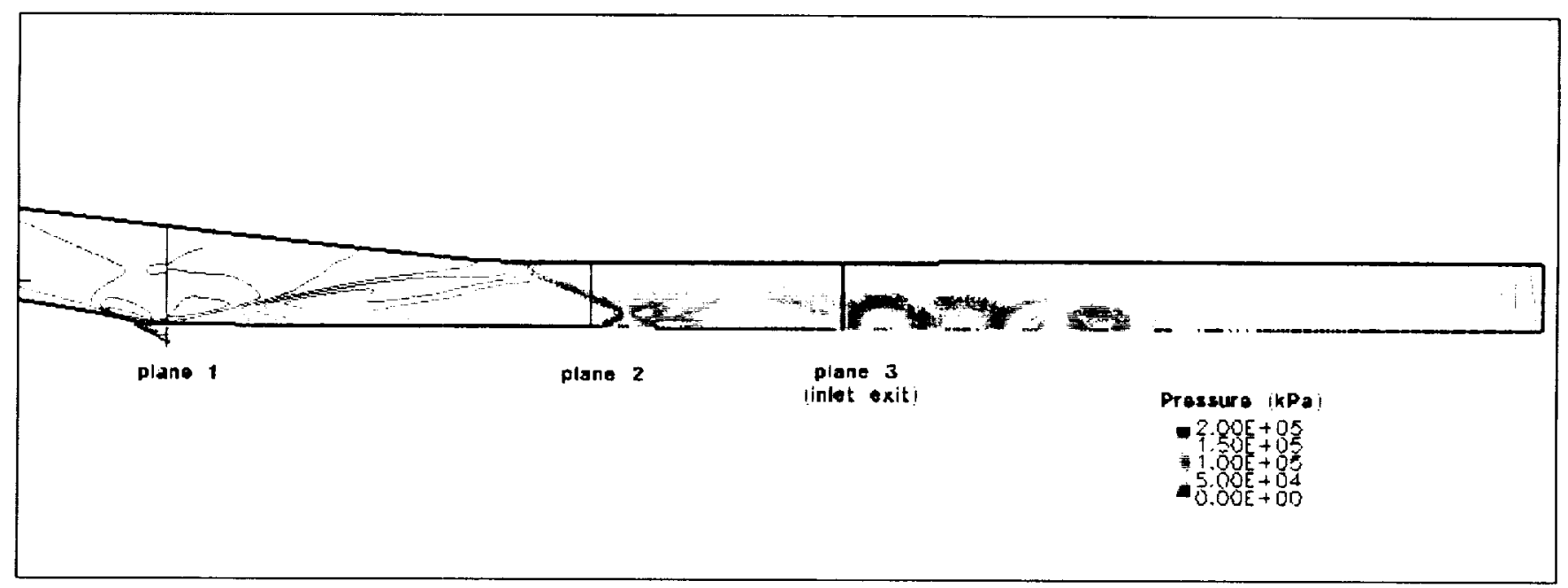

Figure 15 Symmetry plane pressure contours in the back-pressured solution

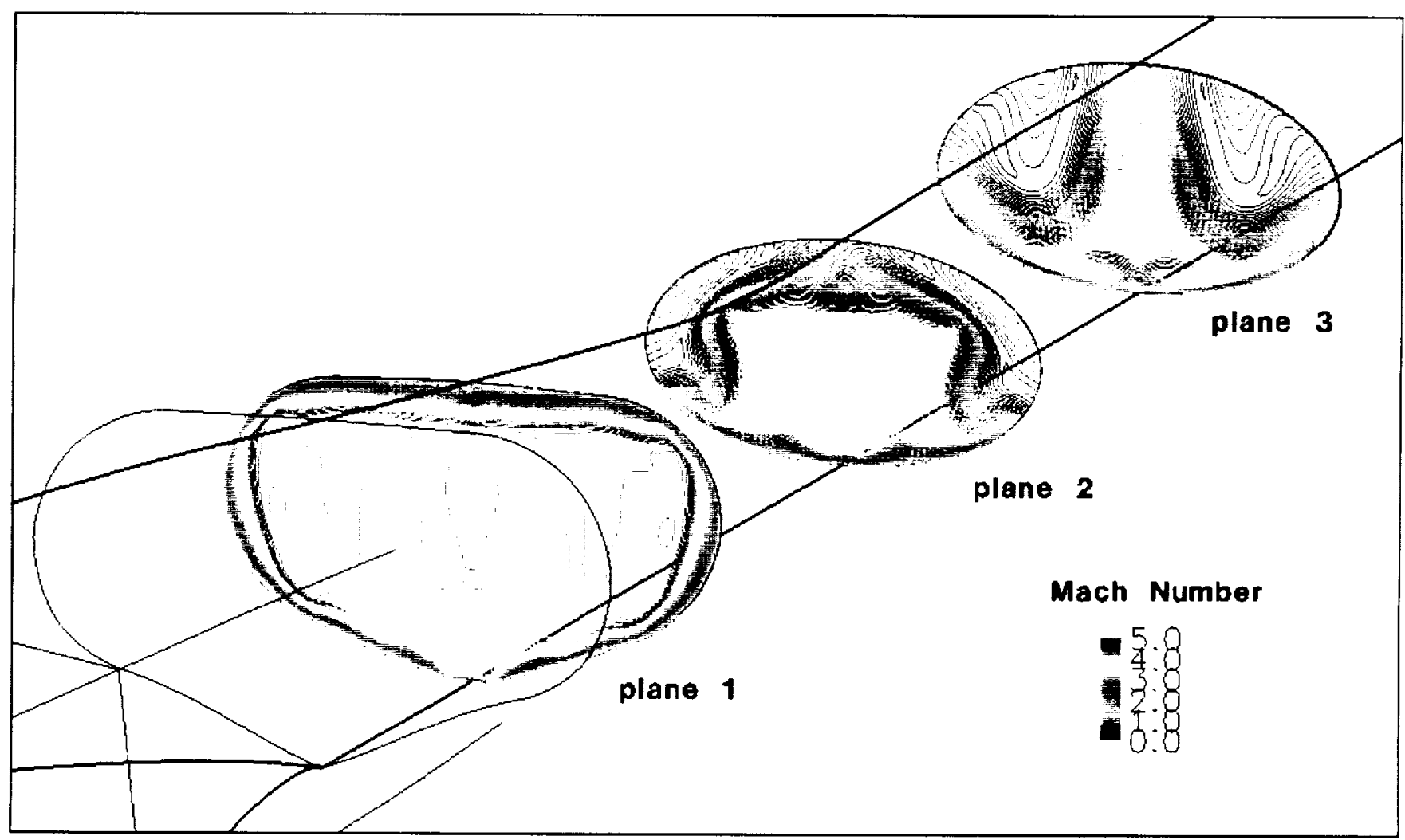

Figure 16 Mach number contours in cross planes in the back-pressured solution 


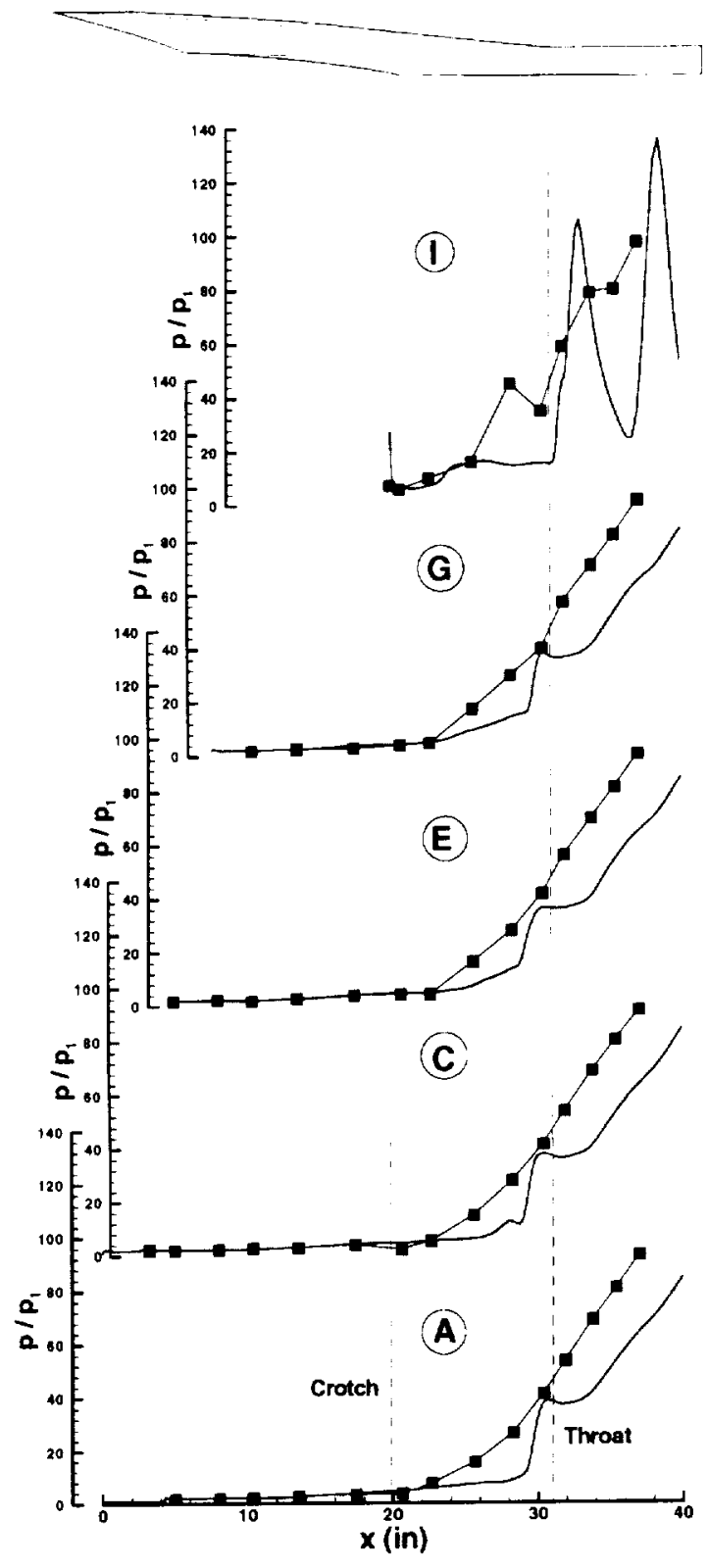

Figure 17 - Surface pressure comparison with backpressure 


